\title{
Acidity Tunable Ionic Liquids as Catalysts for Conversion of Agar into Mixed Sugars
}

\author{
Churl Kim, ${ }^{\dagger}$ Hyun Jin Ryu, Sang Hyoun Kim, Jeong-Jun Yoon, Hoon Sik Kim, ${ }^{\dagger, *}$ and Yong Jin Kim ${ }^{*}$ \\ Green Process R\&D Department, Green Chemistry and Manufacturing System Division, \\ Korea Institute of Industrial Technology, Cheonan, Chungnam 331-825, Korea. ${ }^{*}$ E-mail: yjkim@kitech.re.kr \\ 'Department of Chemistry and Research Institute of Basic Science, Kyung Hee University, Seoul 130-701, Korea \\ Received December 14, 2009, Accepted January 5, 2010
}

Key Words: Ionic liquid, Saccharification, Red algae, Galactose, 5-Hydroxymethylfurfural

As oil prices spike to a new level, the importance of alternative resources and fuels becoming more apparent and the use of bioethanol as an alternative steadily increases around the world. ${ }^{1,2}$ Accordingly, there have been significantly increasing endeavors on the technology development that facilitate the transformation of biorenewables into transportation fuels. To meet this end, many technologies have employed sugar- and corn-based biomass for the industrial production of bioethanol, especially in Brazil and U. S., respectively. While they contributed a lot to the commercialization process, the viability of the so-called $1^{\text {st }}$ generation biofuels is somewhat questionable because of their conflict with food supply. Another key factor influencing biofuel efficacy is whether native ecosystems can be maintained or not. No matter how effective biomass is for producing ethanol, its benefits quickly decrease if all the tropical forests are being razed to make energy crops, leading to another type of a large amount of greenhouse gas (GHG) emission pathway. ${ }^{3}$ To solve this crisis, a new type of biomass should be developed and their biofuels should be produced locally in sustainable systems. From this viewpoint, seaweeds (macro algae) can be an excellent alternative raw material as a new marine biomass for biofuel production. Among them, Gelidium amansii is one most abundantly available red seaweed (Rodophyta) species along the shallow coastal area of many countries. It mainly consists of polysaccharide complexes of fiber and agar whose basic monomer is glucose and galactose residue, respectively.

Generally, there are five major bottom lines for a bioethanol process to be economically viable: the feedstock must be plentiful, inexpensive, in high energy conversion rate, in low demand for food industry, and finally, has to be cultivated in sustainable systems. Accordingly, red seaweed shows very fast growing rate (4 - 6 harvest cycles per year) with high $\mathrm{CO}_{2}$ fixation ability which is $5-7$ times higher than that of a land plant. Furthermore, they can be mass-cultivated using sea water and free sunlight without any need of nitrogen-based fertilizer which has been a significant source of GHG that also destroys stratospheric ozone. ${ }^{4}$ Red seaweed shows very high carbohydrate content up to $75 \%(\mathrm{w} / \mathrm{w})$ based on dried sample and does not cause food supply problems at all. In addition, they do not contain any lignin that has to be eliminated prior to hydrolysis step, which has been a major obstacle to increase production cost in lignocellulosic process. Furthermore, the red seaweed has an ability to absorb nitrogen and phosphorous thereby purifying sea water which leads to oceans' sustainability.
Recently, an effort has been made for the utilization of the fiber extracted from Gelidium amansii, to the making of high quality pulp \& paper. ${ }^{5}$ Therefore, the agar will be an inevitable byproduct during the process of manufacturing red algae-based paper in future. In general, lignocellulosic bioethanol process involves a pretreatment step for delignification to remove lignin contents, which results in somewhat complicated and cost-provoking unit process. In contrast, the pretreatment step for obtaining agar from red seaweed is very simple. The agar and fiber residue can be separated from the original substrate, Gelidium amansii with boiling water. Utilization of marine biomass strategy therefore reduces the number of required unit process dramatically, leading to cutting down the production cost significantly.

Room temperature ionic liquids have been widely applied for task-specific purposes, especially their economical and promising role as active catalysts in organic synthesis. ${ }^{6}$ Despite many efforts that have been devoted to ionic liquids-derived chemical processes, there have been no studies on their catalytic bioconversion process using red seaweed galactan (agar) as a substrate to produce fermentable sugars. In case of agar, the 5-hydroxymethylfurfural (5-HMF) is mainly generated from the degradation of 3,6-anhydrogalactose (AG) due to its acid-labile character. ${ }^{7}$ Using a strong inorganic acid such as $\mathrm{H}_{2} \mathrm{SO}_{4}$ in the saccharification step accelerates the formation of 5-HMF, resulting in pivotal hamper in terms of ethanol fermentation efficacy. Incorporation of ionic liquids with conventional inorganic acid systems may enable to reduce acidity from moderate to weak depending on their type of cation, shedding light on minimizing the generation of 5-HMF.

In this context, various bisulfate-containing acidic ionic liquids as hydrolytic catalysts for the saccharification of agar extracted from Gelidium amansii have been investigated and compared with conventional sulfuric acid system from the viewpoint of sugar yields and 5-HMF formation.

Determination of chemical composition is of great importance since the yields of sugars are calculated based on the compositional analytical data. Normally, acid hydrolysis is a common procedure for determining lignocellulosic biomass, which consists of two-steps: First, hydrolysis with $72 \%(\mathrm{w} / \mathrm{v})$ $\mathrm{H}_{2} \mathrm{SO}_{4}$ at $30^{\circ} \mathrm{C}$ for $2 \mathrm{~h}$, followed by the dilution into $4 \%$ of the reaction mixture and then second hydrolysis at $121^{\circ} \mathrm{C}$ for $1 \mathrm{~h}$. The same methodology was applied to the analysis of Glu and Gal, but $1 \%(\mathrm{w} / \mathrm{v}) \mathrm{H}_{2} \mathrm{SO}_{4}$ was employed for $\mathrm{AG}$ at the first hydrolytic step due to its easy degradation mode. The agar ex- 


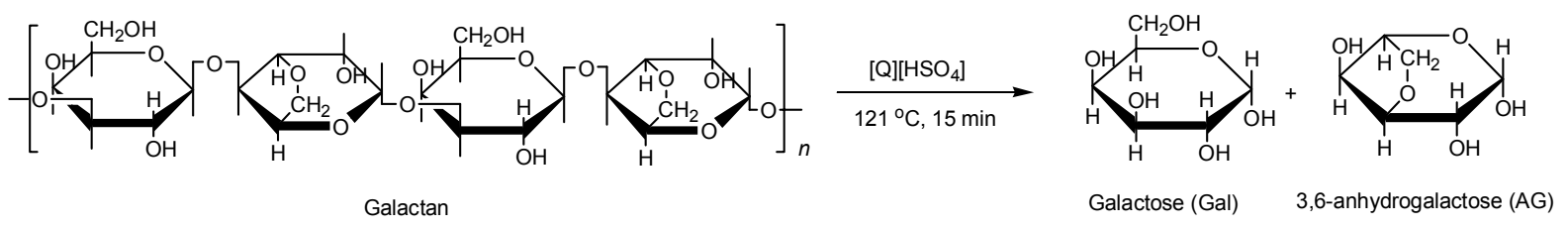

$\mathrm{Q}=$ Choline, Phosphonium, Ammonium, Imidazolium, Morpholium

Scheme 1. Structure of galactan polymer and their hydrolyzed products

Table 1. Sugar compositional analysis data for Gelidium amansii, agar, and fiber

\begin{tabular}{ccccc}
\hline & \multicolumn{4}{c}{ Sugar composition (\%) } \\
\cline { 2 - 5 } Substrate & ${ }^{b}$ Glu & ${ }^{c}$ Gal & ${ }^{d} \mathrm{AG}$ & $\begin{array}{c}\text { Total } \\
\text { carbohydrate }\end{array}$ \\
\hline${ }^{a}$ G.A. & 16.6 & 25.6 & 33.0 & 75.2 \\
Agar & ${ }^{e} 3.0$ & 37.5 & 51.0 & 91.5 \\
Fiber & 92.8 & tr. & 0 & 93.2 \\
\hline
\end{tabular}

$\overline{{ }^{a} \mathrm{G} . \mathrm{A} .}=$ Gelidium amansii $;{ }^{b} \mathrm{Glu}=$ glucose $;{ }^{c} \mathrm{Gal}=$ galactose $;{ }^{d} \mathrm{AG}=3,6-$ anhydrogalactose; ${ }^{e}$ Residue during agar extraction from Gelidium amansii.

tracted from Gelidium amansii is generally classified with red seaweed galactan which is composed of repeating agarobiose unit of alternating 1,3-linked-D-galactose and 1,4-linked 3,6anhydrous-L-galactose residues. ${ }^{6}$ Once the agar is hydrolyzed, D-galactose (Gal) and 3,6-anhydrogalactose (AG) are released (Scheme 1). Based on the theoretical structure of repeating agarobiose unit of galactan, equal molar amounts of Gal and $\mathrm{AG}$ are expected, but experimental composition ratio of Gal to $\mathrm{AG}$ ranges from 0.9 to 1.2 depending on the species. ${ }^{7-9}$ The result of the sugar compositional analysis for Gelidium amansii, agar, and fiber is summarized in Table 1. The total sugar content of Gelidium amansii is found to be $75.2 \%$ with AG being the dominant monosaccharide in the cell wall polysaccharide fraction. The total amount of sugar in agar and fiber are $91.5 \%$ and $93.2 \%$, respectively. From these analytical results, the theoretical maximum concentration of Gal and $\mathrm{AG}$ were found to be 19 and 26 $\mathrm{g} / \mathrm{L}$ at the $\mathrm{S} / \mathrm{L}$ (solid/liquid) ratio of $5 \%$ and 38 and $51 \mathrm{~g} / \mathrm{L}$ at $10 \%$ of $\mathrm{S} / \mathrm{L}$, respectively.

The effect of various sulfuric acid concentrations on the product distribution is evaluated at the $\mathrm{S} / \mathrm{L}$ ratio of $5 \%$ at $121{ }^{\circ} \mathrm{C}$ for $15 \mathrm{~min}$ in autoclave. The results in Figure 1 show that the concentration of Gal increases very slowly with increasing amount of sulfuric acid up to $6.1 \mathrm{mmol}$, giving $18.6 \mathrm{~g} / \mathrm{L}(98 \%$ yield), whereas the AG concentration decreases sharply due to its easy conversion into 5-HMF, resulting in concentration around $7.5 \mathrm{~g} / \mathrm{L}$ at $4.1 \mathrm{mmol}$ of sulfuric acid. According to a preliminary study, the 5 -HMF concentration above $5 \mathrm{~g} / \mathrm{L}$ plays a crucial role in inhibiting fermentation process when using red seaweed hydrolysates. ${ }^{10}$ Therefore a different strategy has been undertaken to reduce the formation of 5-HMF. Due to the aforementioned acid-labile character of AG, an acidic ionic liquid was tested, which may provide a milder condition than sulfuric acid and to study what differences this acidic ionic liquid may impart on product distribution such as Gal, AG, and 5-HMF formation. The same hydrolysis was performed in the presence

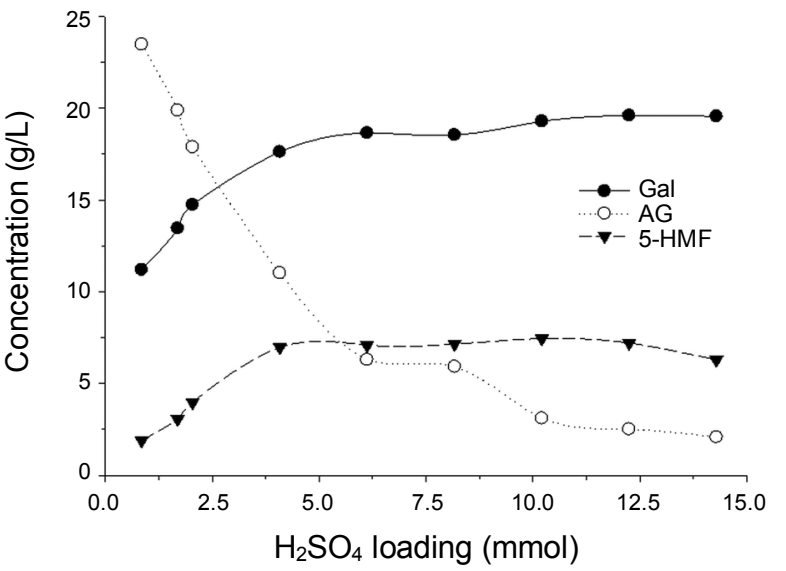

Figure 1. Effect of sulfuric acid loading on the sugar and 5-HMF formation. Conditions: $\mathrm{S} / \mathrm{L}$ ratio $=5 \%$, Agar $=5 \mathrm{~g}, \mathrm{DI}-\mathrm{H}_{2} \mathrm{O}=100 \mathrm{~mL}$, $\mathrm{T}=121{ }^{\circ} \mathrm{C}, t=15 \mathrm{~min}$.

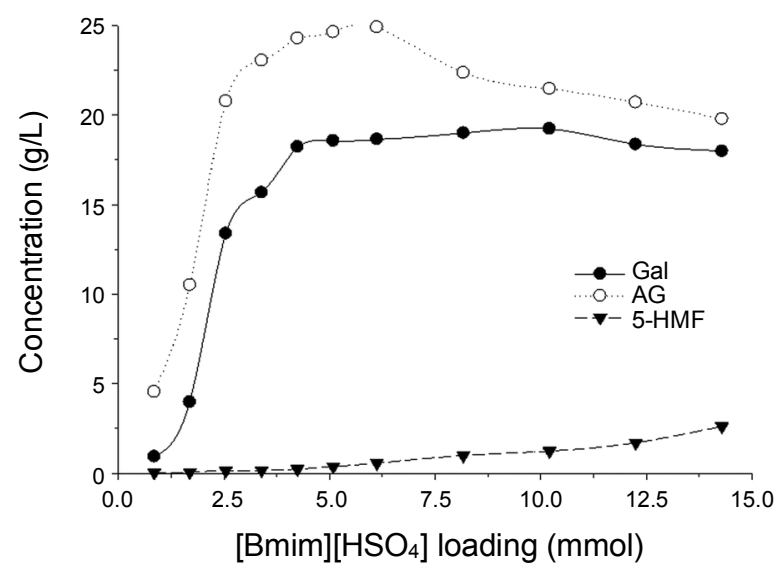

Figure 2. Effect of $[\mathrm{Bmim}]\left[\mathrm{HSO}_{4}\right]$ loading on the sugar and 5-HMF formation. Conditions: $\mathrm{S} / \mathrm{L}$ ratio $=5 \%$, Agar $=5 \mathrm{~g}, \mathrm{DI}-\mathrm{H}_{2} \mathrm{O}=100$ $\mathrm{mL}, \mathrm{T}=121^{\circ} \mathrm{C}, t=15 \mathrm{~min}$.

of $[\mathrm{Bmim}]\left[\mathrm{HSO}_{4}\right]$ as a model compound and the results illustrated in Figure 2 show that $\mathrm{Gal}$ concentration increased spontaneously with the increase in [Bmim] $\left[\mathrm{HSO}_{4}\right]$ up to $4.2 \mathrm{mmol}$, reaching $18.2 \mathrm{~g} / \mathrm{L}$ of Gal ( $96 \%$ yield). In addition, AG yields concomitantly increased with the increase in $[\mathrm{Bmim}]\left[\mathrm{HSO}_{4}\right]$ concentration, leading to $24.9 \mathrm{~g} / \mathrm{L}$ ( $96 \%$ yield) at $6.1 \mathrm{mmol}$ of catalyst loading. It is also worth noting that the formation of 5-HMF was very negligible, ranging from 0.03 to $0.37 \mathrm{~g} / \mathrm{L}$ at the same amount of ionic liquid loading, suggesting $95 \sim 99 \%$ reduction effect in the formation of 5-HMF compared with $\mathrm{H}_{2} \mathrm{SO}_{4}$.

To test other ionic liquids in order to find out a more effective 


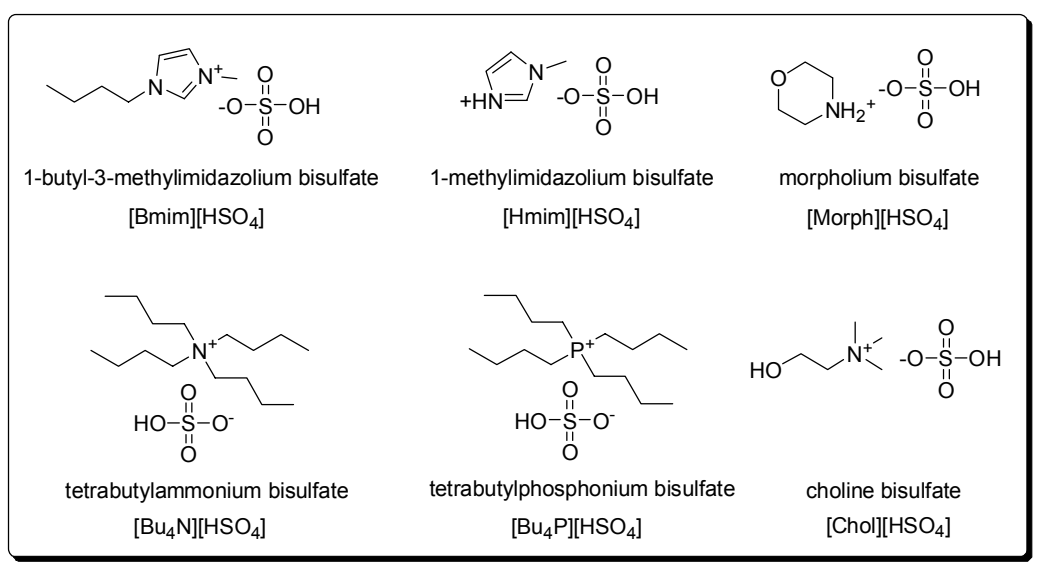

Scheme 2. Various bisulfate ionic liquids as catalysts for the agar saccharification

Table 2. Effect of various bisulfate ionic liquids on the product distribution $^{a}$

\begin{tabular}{|c|c|c|c|c|c|c|}
\hline \multirow{3}{*}{ Entry } & \multirow{3}{*}{ Catalyst } & \multicolumn{5}{|c|}{ Product distribution } \\
\hline & & \multicolumn{2}{|c|}{ Gal } & \multicolumn{2}{|r|}{$\mathrm{AG}$} & \multirow{2}{*}{$\frac{5-\mathrm{HMF}}{\mathrm{g} / \mathrm{L}}$} \\
\hline & & $\mathrm{g} / \mathrm{L}$ & yield $(\%)$ & $\mathrm{g} / \mathrm{L}$ & yield $(\%)$ & \\
\hline 1 & $\mathrm{H}_{2} \mathrm{SO}_{4}$ & 35.6 & 93.7 & 35.9 & 70.4 & 7.5 \\
\hline 2 & {$[\mathrm{Bmim}]\left[\mathrm{HSO}_{4}\right]$} & 29.5 & 77.6 & 27.8 & 54.5 & 0.8 \\
\hline 3 & {$[\mathrm{Hmim}]\left[\mathrm{HSO}_{4}\right]$} & 29.3 & 77.1 & 32.3 & 63.3 & 1.0 \\
\hline 4 & {$[\mathrm{Morph}]\left[\mathrm{HSO}_{4}\right]$} & 8.6 & 22.6 & 31.1 & 61.0 & 0.5 \\
\hline 5 & {$[\mathrm{Chol}]\left[\mathrm{HSO}_{4}\right]$} & 36.6 & 96.3 & 51.1 & 99.9 & 1.3 \\
\hline 6 & {$\left[\mathrm{Bu}_{4} \mathrm{P}\right]\left[\mathrm{HSO}_{4}\right]$} & 35.6 & 93.7 & 48.1 & 94.3 & 1.6 \\
\hline 7 & {$\left[\mathrm{Bu}_{4} \mathrm{~N}\right]\left[\mathrm{HSO}_{4}\right]$} & 33.7 & 88.7 & 47.1 & 92.4 & 2.0 \\
\hline
\end{tabular}

${ }^{a}$ Conditions: Catalyst $=3.0 \mathrm{mmol}, \mathrm{S} / \mathrm{L}$ ratio $=10 \%$, Agar $=10 \mathrm{~g}, \mathrm{DI}-\mathrm{H}_{2} \mathrm{O}=$ $100 \mathrm{~mL}, \mathrm{~T}=121{ }^{\circ} \mathrm{C}, t=15 \mathrm{~min}$.

hydrolytic system, a series of bisulfate ionic liquids (Scheme 2) were synthesized according to a literature method. ${ }^{11}$ These were then applied for the catalytic agar saccharification at the $\mathrm{S} / \mathrm{L}$ ratio of $10 \%$ at $121{ }^{\circ} \mathrm{C}$ for $15 \mathrm{~min}$ in autoclave and their performance was compared with $\mathrm{H}_{2} \mathrm{SO}_{4}$ hydrolytic result. The molar amount of all the catalysts was set to $3.0 \mathrm{mmol}$ and the results are shown in Table 2. As already seen in Figure $1, \mathrm{H}_{2} \mathrm{SO}_{4}$ delivered $7.5 \mathrm{~g} / \mathrm{L}$ of 5 -HMF which is sufficiently high to the degree of hampering the fermentation. The ring structure in cationic part, imidazolium- and morpholium-based bisulfate ionic liquids (Table 2, entries 2-4) afford relatively low Gal and AG concentration with negligible amount of 5-HMF in less than $1 \mathrm{~g} / \mathrm{L}$. Interestingly, non ring structural ammonium-, phosphonium-, and choline-based ionic liquids (Table 2, entries 5-7) show fairly high Gal and AG yields with a very small amount of 5-HMF formation in less than $2 \mathrm{~g} / \mathrm{L}$ at the same amount of catalyst loading. Among them, the $[\mathrm{Chol}]\left[\mathrm{HSO}_{4}\right]$ ionic liquid synthesized from the reaction of sulfuric acid and commercially available choline chloride provides the best result that shows very high Gal as well as AG yields at the same catalyst loading.

From these results, the activity of ionic liquids influencing Gal and AG yields are classified into, high and low depending upon the cation type of ionic liquids used. The reason for the suppression of 5-HMF generation as well as the well-balanced

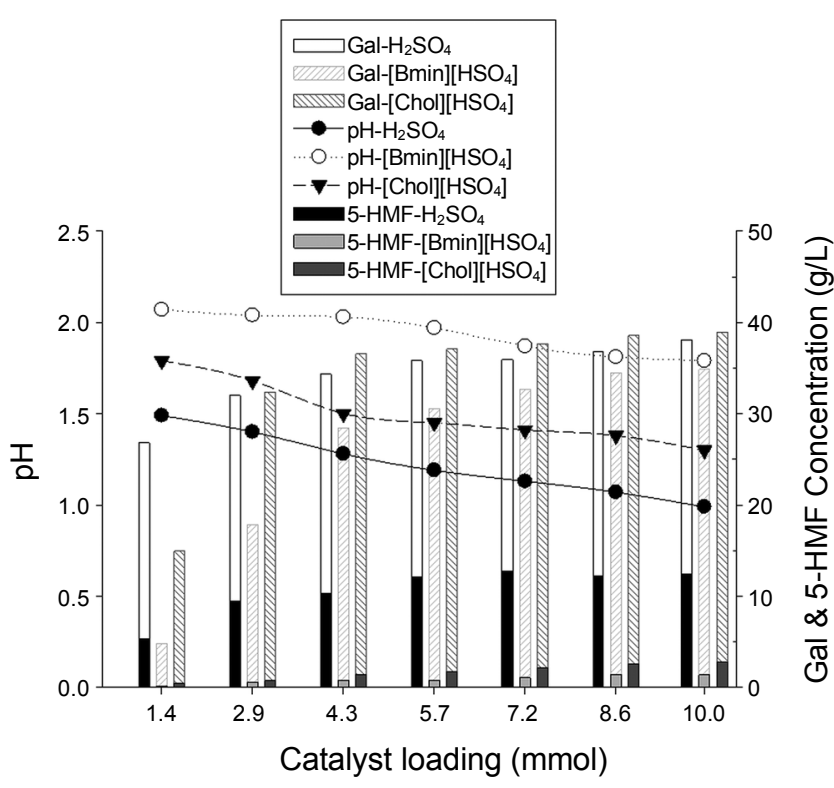

Figure 3. Effects of various catalysts loading on the $\mathrm{pH}$ and galactose concentration. Conditions: $\mathrm{S} / \mathrm{L}$ ratio $=10 \%$, Agar $=10 \mathrm{~g}, \mathrm{DI}-\mathrm{H}_{2} \mathrm{O}=$ $100 \mathrm{~mL}, \mathrm{~T}=121^{\circ} \mathrm{C}, t=15 \mathrm{~min}$.

sugar distribution without the degradation of AG to form 5-HMF using these ionic liquids cannot be fully explained at the moment, but it is likely that the type of cation of ionic liquids plays a significant role in regulating or, at least, reducing brønsted acidity of bisulfate anion $\left.\left(\left[\mathrm{HSO}_{4}\right]\right]^{-}\right)$. This is partially supported by simple measurement of $\mathrm{pH}$ value using the same molar amount of several ionic liquid catalysts, which may help to derive some clues from the acidity-reactivity correlations.

To correlate the findings, a separate hydrolysis reaction was carried out in the presence of three types of representative catalysts $\left(\mathrm{H}_{2} \mathrm{SO}_{4},[\mathrm{Bmim}]\left[\mathrm{HSO}_{4}\right]\right.$, and $\left.[\mathrm{Chol}]\left[\mathrm{HSO}_{4}\right]\right)$ at the $\mathrm{S} / \mathrm{L}$ ratio of $10 \%$ at $121{ }^{\circ} \mathrm{C}$ for $15 \mathrm{~min}$ in an autoclave. The results illustrated in Figure 3 indicate that $\mathrm{H}_{2} \mathrm{SO}_{4}$ shows the lowest $\mathrm{pH}$, $[\mathrm{Chol}]\left[\mathrm{HSO}_{4}\right]$ is located at the midpoint, and [Bmim] $\left[\mathrm{HSO}_{4}\right]$ reveals the highest value in the $\mathrm{pH}$ determining curve. The lowering in acidity upon incorporation of ionic liquids can be ascribed to a depletion of the proton in sulfuric acid to give the 
bisulfate-based ionic liquids. Accordingly, $\mathrm{H}_{2} \mathrm{SO}_{4}$ and [Chol] $\left[\mathrm{HSO}_{4}\right]$ show good activity for the formation of Gal in the overall catalyst loading and $[\mathrm{Bmim}]\left[\mathrm{HSO}_{4}\right]$ shows the lowest Gal release. Although $\mathrm{H}_{2} \mathrm{SO}_{4}$ shows a high yield towards $\mathrm{Gal}$, the generation of 5-HMF is significant, probably due to the acid labile-induced degradation of AG to 5-HMF. This can be attributed to the brønsted acidity of $\mathrm{H}_{2} \mathrm{SO}_{4}$. In contrast, [Chol] [ $\left.\mathrm{HSO}_{4}\right]$ ionic liquid which shows a lower brønsted acidity than $\mathrm{H}_{2} \mathrm{SO}_{4}$ in terms of $\mathrm{pH}$, shows very high Gal yield with reduced 5-HMF formation. It demonstrates that $[\mathrm{Chol}]\left[\mathrm{HSO}_{4}\right]$ has an acidity enough to depolymerize galactan to afford high yields of Gal and to prevent $\mathrm{AG}$ from degradation to 5-HMF. The AG yields were found to be more than $95 \%$ in the presence of [Chol] $\left[\mathrm{HSO}_{4}\right]$ (data not shown in Figure 3). Further investigation on the effect of different type of cation (ring structure $v s$. non-ring structure) on the acidity-reactivity relationship is under progress.

To summarize, various factors affecting yields of Gal, AG, and 5-HMF formation during saccharification were investigated using agar as a substrate in the presence of several bisulfatebased acidic ionic liquids as catalysts. The result was compared with employing sulfuric acid from the viewpoint of sugar yields and 5-HMF formation. [Bmim] $\left[\mathrm{HSO}_{4}\right],[\mathrm{Hmim}]\left[\mathrm{HSO}_{4}\right]$, [Morph] $\left[\mathrm{HSO}_{4}\right],\left[\mathrm{Bu}_{4} \mathrm{~N}\right]\left[\mathrm{HSO}_{4}\right],\left[\mathrm{Bu}_{4} \mathrm{P}\right]\left[\mathrm{HSO}_{4}\right],[\mathrm{Chol}]\left[\mathrm{HSO}_{4}\right]$ showed moderate to high yields of $\mathrm{Gal}$ and $\mathrm{AG}$ with a remarkable decrease in 5-HMF formation compared with sulfuric acid. Among them, $[\mathrm{Chol}]\left[\mathrm{HSO}_{4}\right]$ ionic liquid was found to exhibit the highest yield of sugars with an acceptable concentration of 5-HMF that does not inhibit the fermentation process.

\section{Experimental Section}

Hydrolytic Reaction. The representative agar saccharification reaction is as follows: A mixture of $10 \mathrm{~g}$ of extracted agar from Gelidium amansii and a $100 \mathrm{~mL}$ of aqueous solution containing acidic ionic liquids were charged in an autoclave. The hydrolytic reaction was carried out at a temperature of $121{ }^{\circ} \mathrm{C}$ for $15 \mathrm{~min}$. Then, the $\mathrm{pH}$ of the hydrolysates was adjusted to 5.5 by adding $\mathrm{CaCO}_{3}$. After this pre-treatment, the liquid was separated by centrifugation and analyzed for sugar concentration.

Synthesis of Choline bisulfate ([Chol] $\left.\left[\mathrm{HSO}_{4}\right]\right) .^{12}$ The representative synthesis of Choline bisulfate is as follows: Choline chloride $(50 \mathrm{~g})$ was charged into a $500 \mathrm{~mL}$ round-bottom flask and a stoichiometric amount of dilute sulfuric acid (50\%, 35.93 $\mathrm{mL}$ ) was added drop wise very slowly and then the mixture was stirred for $24 \mathrm{~h}$ at room temperature. The resulting solid was washed repeatedly with ethyl acetate to remove non-ionic residues followed by drying in vacuum to give a white solid. The resulting ionic liquid was further purified by recrystallization with methylene chloride. ${ }^{1} \mathrm{H}$ NMR $\left(200 \mathrm{MHz}, \mathrm{D}_{2} \mathrm{O}\right) \delta$ $1.78(\mathrm{~s}, 1 \mathrm{H}), 3.61(\mathrm{~d}, 3 \mathrm{H}), 7.12(\mathrm{~d}, 2 \mathrm{H}), 8.38$ (d, 2H). IR (KBr, $\mathrm{cm}^{-1}:$ 3040, 1220, 1036. Anal. Calcd. for $\mathrm{C}_{5} \mathrm{H}_{15} \mathrm{NO}_{5} \mathrm{~S}$ : C, 29.84; $\mathrm{H}, 7.51$; N, 6.96; O, 39.75; S, 15.93. Found: C, 32.72; H, 7.33; N, 7.60; O, 28.95; S, 19.17. MS (EI) $m / z: 201.07\left(\mathrm{M}^{+}\right)$.

Acknowledgments. This work was supported by the Korea Institute of Energy Technology Evaluation and Planning (KETEP) grant funded from the Ministry of Knowledge Economy (MKE) of Korea.

\section{References}

1. Hermann, B. G.; Blok, K. M.; Patel, K. Environ. Sci. Technol. 2007, 41,7915-7921.

2. Tao, F.; Miao, J. Y.; Shi, G. Y.; Zhang, K. C. Process Biochemistry 2005, 40, 183-187.

3. Righelato, D; Sprakcklen, D. V. Science 2007, 315, 902-904.

4. Scharlemann, J. P. W.; Laurance, W. F. Science 2008, 319, 43-44.

5. (a) PCT/KR2004/002939. (b) Korea patent 10-0512793, 2005.

6. (a) Kim, Y. J.; Varma, R. S. J. Org. Chem. 2005, 70, 7882-7891.

(b) Stracke, M. P.; Migliorini, M. V.; Lissner, E. H.; Schrekker, S.; Dupont, J.; Goncalves, R. S. Applide Energy 2009, 86, 1512-1516. (c) Kim, H. S.; Kim, Y. J.; Lee, H.; Park, K. Y.; Lee, C.; Chin, C. S. Angew. Chem. Int. Ed. 2002, 41, 4300-4303.

7. Jol, C. N.; Neiss, T. G.; Penninkhof, B.; Rudolph, B.; De Ruiter, G. A. Anal. Biochem.1999, 268, 213-222.

8. Quemener, B.; Lahaye, M. J. Appl. Phycology 1998, 10, 75-81.

9. (a) Hama, Y.; Nakagawa, H.; Kurosawa, M.; Sumi, T.; Xia, X.; Yamaguchi, K. Anal. Biochem. 1998, 265, 42-48. (b) Navarro, D. A.; Stortz, C. A. Carbohydrate Research 2003, 338, 2111-2118.

10. Manuscript in preparation.

11. (a) Sonu, N. G.; Kad, G. L.; Singh, J. Catal. Comm. 2007, 8, 13231328. (b) Hajipour, A. R.; Khazdooz, L.; Ruoho, A. E. Catal. Comm. 2008, 9, 89-96. (c) Yadav, L. D.; Srivastava, V. P.; Patel, R. Tetrahedron Lett. 2008, 49, 3142-3146.

12. The supporting information on the synthesis and characterization of other bisulfate-based acidic ionic liquids is available on request from the correspondence author (Fax: +82-41-589-8580, E-mail: yjkim@kitech.re.kr). 